\title{
Morbidity from ischemic heart disease in workers at a stainless steel welding factory
}

\author{
Bjørn Hilt, MD, Torgunn Qvenild og Olve Rømyhr, MSc \\ Department of Occupational Medicine, University Hospital of Trondheim, and \\ Institute of Environmental Medicine, Faculty of Medicine, Norwegian University of Science and Technology \\ Correspondence: Bjørn Hilt, Department of Occupational Medicine, University Hospital of Trondheim, N-7006 Trondheim, Norway \\ Telephone: +4773867515 Telefax: +47 73868970 e-mail: bjorn.hilt@medisin.ntnu.no
}

\begin{abstract}
Objectives: To investigate whether there was an increased morbidity from cardiovascular diseases (CVD) among welders and other workers at a stainless steel welding factory, and, if so, to see whether morbidity could be linked to specific exposure factors.

Methods: All the men who had worked at the plant for more than one year since 1960, and who were under the age of 70 years at the time of the study, were included in the study group. The control group was randomly selected from the male population of the same town, and was categorically matched for age. A self administered questionnaire was used to collect information on the occurrence of CVD and related symptoms, background variables, and exposure factors. The validity of the outcome variables for a subgroup of the participants was checked with their appointed general practitioners. This validation revealed a low sensitivity and a high specificity for the outcome variables "chest pain on exercise" and "angina pectoris", while for "myocardial infarction" both the sensitivity and the specificity of the answers given were high.

Results: There were 236 men from the study group and 989 men from the control group who fulfilled the inclusion criteria, and who answered the questionnaires. The bivariate analysis showed that the study group had an increased age and smoking adjusted prevalence of "chest pain on exercise" and "angina pectoris" with ratios $2.3(95 \%$ CI $1.5-4.9)$ and 2.6 (95\% 1.2-5.7) respectively. When using multiple logistic regression analysis with control for potential confounding factors, the odds ratios for the study group as compared to the control group, were 2.6 (95\% CI 1.3-5.3) for "chest pain on exercise", 2.5 (95\% CI 1.1-5.8) for "angina pectoris", and 2.4 (95\% CI 1.1-4.9) for myocardial infarction. The only explanatory variable which showed statistically significant increased odds ratios for all three outcome variables was work with grinding, with 2.4 (95\% CI 1.0-5.5), $3.3(1.3-8.5)$, and 2.5 (1.1-5.9) respectively.

Conclusion: In accord with some other studies, the results of the study support a hypothesis that there may be a relation between exposure factors to which stainless steel metal workers are exposed and an increased risk of ischemic heart disease.
\end{abstract}

Key terms: Angina pectoris, cardiovascular diseases, grinding, ischemic heart disease, metal workers, myocardial infarction, stainless steel, welding

\section{INTRODUCTION}

Even though cardiovascular diseases (CVD) are the most common cause of death in most western societies, relatively little is known about chemical occupational exposure factors that can cause such diseases. So far, the main focus has been on exposure to carbon disulphide as a cause of ischemic heart disease (IHD), carbon monoxide as an acute inducer of ischemic attacks, and halogenated hydrocarbons leading to acute dysrythmias of the heart $(1,2)$. Among the nonchemical factors, stress is probably the factor which is most strongly recognized as having a relation to the occurrence of CVD (3). Other non-chemical factors which are known to have, or are suspected of having, impact on the risk of CVD are shift work, noise, physical inactivity, heat, and cold $(2,4)$.
There have been two previous reports connecting mortality from IHD with metal work. In 3,500 shipyard workers from north-east England there was an increased mortality from IHD among the welders, with a standardized mortality ratio (SMR) of $130(95 \% \mathrm{CI}$ 104-162). Other groups of workers did not show a similar increase (5). An other investigation of 9,404 workers from 13 metal factories in France also found that welders had an increased mortality of IHD with SMR 151 (95\% CI 100-218). SMR was more increased in stainless steel welders, and also showed a positive association with the length of employment as a welder (6). In addition, a recently published registry study from Denmark and Sweden has shown an increased mortality from IHD in metal workers in general (7). As to the possible pathophysiological mechanisms for a connection between welding fumes and 
dust and IHD, an interesting hypothesis has emerged during the last years. The hypothesis raises the question whether a local inflammation in the bronchial mucosa induced by inhalation of respiratory irritants may stimulate the production of fibrinogen and thus lead to IHD (8).

The present study was initiated by the occupational health service of a welding factory predominantly producing different equipment for industry and agriculture from stainless steel. There they had had the impression for some time that there could be an increased incidence of CVD in the employees.

The goal of the present study was to investigate whether there was an increased morbidity from CVD in welders and other workers at the plant, and, if so, to see whether it could be linked to specific exposure factors.

\section{SUBJECTS AND METHODS}

The company has been operating as a welding plant since 1920. Complete personnel registers were available from 1960. All the men who had worked at the plant for more than one year since 1960, and who were under the age of 70 years at the time of the study in 1993 were included in the study group. There were 365 men in the personnel register who fulfilled the inclusion criteria for the study group. Among them, 23 were deceased, two had moved abroad, and twelve could not be traced. Thus, 328 men were eligible for the study group.

In order to get a control group of sufficient size of men who were not working in the same kind of industry, we chose to use men from the general population as a control group. They were randomly chosen from the census register of the town where the plant was located, and categorically matched for age. According to these criterias 1,600 men were chosen for the control group. Of these, two were deceased since the last update of the register, six already belonged to the study group, four were mentally disturbed, 10 had moved abroad, and 17 could not be traced. That left us with 1,561 men eligible for the control group. There were 1,159 men (74\%) who responded by answering a questionnaire. Two further restrictions, which were based on the answers to the questionnaire, was that they should not be metal workers, and that they should have been occupationally active for at least five years since 1960. Due to this restriction 170 of the responders were excluded from the control group, leaving 989 men for analysis.

Data on occupational exposure factors, the occurrence of CVD and related symptoms and lung diseases and symptoms, as well as life style factors and other potential confounding factors, were collected from both groups by means of a mailed self-administered questionnaire. The inquiry about occuaptional exposure factors included questions about metal work and shift work, and about exposures to noise, heat, stress, vibration, and fluorocarbons. One reminder was sent to non-responders.

In addition to the answers to the questionnaire, information on exposure factors at the plant was gathered by an experienced occupational hygienist (OR). The number of production workers at the plant had varied from about 170 around 1970 to about 50 at the time of the study. Their main tasks had been stainless steel welding and grinding. There were special grinders up to about 1985, while today almost all production workers do both tasks. The main welding methods were tungsten inert gas welding (TIG), metal inactive/ active gas welding (MIG/MAG), and manual metal arc welding (MMA). While the amount of MMA welding had decreased, the proportions of the welding methods used at the time of the study were $60 \%$ TIG, $10 \%$ MIG/MAG, and 30\% MMA. Dust measurements in connection with welding which were performed by the local labour inspection (10 samples) in 1976 showed a mean concentration of total dust of $4.1 \mathrm{mg} / \mathrm{m}^{3}$, and of total chromium and nickel of 0.1 and $0.04 \mathrm{mg} / \mathrm{m}^{3}$ respectively. No such measurements were available for the grinding operations. The use of personal protective equipment in connection with welding and grinding was deficient until recent years. There has also been some work at the plant entailing insulation with polyurethane foam, and the installation of refrigerators for the stainless steel tanks which entailed a possible exposure to fluorocarbons.

Based on the answers from the respondents about their working tasks, the study group was divided into 46 workers with probably no exposure to dust or gases from welding and grinding, 40 workers with probably indirect exposures only, and 150 workers who had been working directly with welding or grinding.

In order to assure the quality of the questionnaire data regarding CVD morbidity, we obtained permission from each participant to check their health information with their appointed general practitioners. This was checked for two subgroups of 85 men from the study group and 203 men from the control group.

All data were computed by means of the program Data Ease and analyzed by means of the Statistical Programme for Social Sciences (SPSS/PC+) and EpiInfo. In the bivariate analyses the prevalences of CVD and respiratory diseases/symptoms were adjusted for age and smoking habits by a standard direct method. Statistical significance of the prevalence ratios was calculated by the Mantel-Haenzel method. For all tests differences were considered as statistically significant on a $5 \%$ level $(\mathrm{p}<0.05)$.

Multivariate logistic regression analyses were carried out for selected outcome variables in relation to exposure groups and specific exposure factors. Potential confounding factors that showed differences between the groups which we considered could influence the results, were included in the models.

The study was approved by the Regional ethical committee for medical research. 


\section{RESULTS}

Among the 328 men eligible for the study group, 236 $(72 \%)$ responded to the questionnaire. Among the 1,561 eligible for the control group, $1,159(74 \%)$ answered. With the further restriction the control group consisted of 989 men eligible for analysis. The average length of employment for the members of the study group at the plant was twelve years.

Table 1 shows background characteristics of the two groups in terms of age, smoking habits, length of education, and other potential confounding factors. The use of milk refers to the intake of whole milk, while the use of coffee refers to the use of boiled coffee which has been connected with increased risk of IHD (9). The use of butter also includes margarine based on animal fat, and the use of extra salt refers to those who usually put extra salt on their food. There were differences between the two groups regarding smoking habits, occurrence of CVD among first degree relatives under the age of 50 years, and length of education.

Age and smoking adjusted prevalences of CVD and related symptoms are presented in table 2 . The phrasing of the questions regarding symptoms was: "Do you get chest pain on exercise?" and if so "how often?" (with fixed options), and "How do you consider your heart function at present?". The questions regarding diseases asked if they had or had had the diseases inquired about. We used a colloquial expression for angina pectoris. The prevalences of chest pain during excercise and angina pectoris showed statistically significant differences between the groups. There was also a statistically significant greater proportion of men in the control group who considered their heart function to be "very good".

Table 3 shows the prevalences of chronic bronchitis, defined as cough with phlegm for at least three months during two ensuing years, and respiratory symptoms in the two groups adjusted for age and smoking habits. The phrasing of the questions was based on the MRC questionnaire (10). Light dyspnoe was defined as more dyspnoe than men of the same age when walking up a hill or two stairs, while severe dyspnoe was defined as dyspnoe when walking on plain ground or at rest. All prevalence ratios were slightly increased, but on a $5 \%$ level there were no statistically significant differences between the study group and the control group.

Table 1. Characteristics of the study group with 236 stainless steel metal workers and the control group consisting of 989 men from the general population with regard to age, smoking habits, and other potential confounding factors (figures in \% when not stated otherwise).

\begin{tabular}{|c|c|c|}
\hline Characteristics & $\begin{array}{l}\text { Study group } \\
(\mathrm{n}=236)\end{array}$ & $\begin{array}{c}\text { Control group } \\
(\mathrm{n}=989)\end{array}$ \\
\hline$\overline{\text { Age, mean (SD) }}$ & $48.0(12.1)$ & $47.0(11.8)$ \\
\hline Smoking habits & & \\
\hline Daily smokers & 44.1 & 41.6 \\
\hline Ex-smokers & 27.5 & 21.5 \\
\hline Never smokers & 26.7 & 34.7 \\
\hline $\begin{array}{l}\text { Grams of tobacco pr. week } \\
\text { for current smokers }\end{array}$ & 44.3 & 42.7 \\
\hline Education $>10$ years & 52.7 & 68.3 \\
\hline $\begin{array}{l}\text { Physical training } \\
<1 \text { hour pr week }\end{array}$ & 39.0 & 39.1 \\
\hline $\begin{array}{l}\text { CVD among first degree } \\
\text { relatives }<50 \text { years of age }\end{array}$ & 19.5 & 14.9 \\
\hline $\begin{array}{l}\text { More than } 4 \text { glasses of } \\
\text { milk pr. day }\end{array}$ & 12.7 & 12.9 \\
\hline $\begin{array}{l}\text { More than } 4 \text { cups of } \\
\text { boiled coffee pr. day }\end{array}$ & 13.1 & 11.4 \\
\hline Use of butter on the bread & 23.3 & 20.5 \\
\hline Use of extra salt on the food & 30.7 & 30.8 \\
\hline Body mass index, mean (SD) & $25.2(2.7)$ & $25.1(3.2)$ \\
\hline
\end{tabular}

Table 2. Prevalences of CVD and related symptoms directly adjusted for age and smoking habits in 236 stainless steel metal workers (study group) and a control group of 989 men from the general population.

\begin{tabular}{lcccc}
\hline Disease/symptom & $\begin{array}{c}\text { Study group } \\
(\mathrm{n}=236)\end{array}$ & $\begin{array}{c}\text { Control group } \\
(\mathrm{n}=989)\end{array}$ & $\begin{array}{c}\text { Prevalence } \\
\text { ratio }\end{array}$ & $\begin{array}{c}95 \% \text { confidence } \\
\text { interval }\end{array}$ \\
\hline Myocardial infarction & 4.3 & 3.1 & 1.37 & $0.7-2.8$ \\
High blood pressure & 12.6 & 11.7 & 1.08 & $0.7-1.6$ \\
Heart failure & 0.8 & 1.4 & 0.64 & $0.2-2.8$ \\
Heart rythm disturbances & 10.6 & 12.9 & 0.83 & $0.6-1.2$ \\
Angina pectoris & 4.1 & 1.6 & 2.61 & $1.2-5.7$ \\
Chest pain on excercise & & & & \\
$\quad$ "often, almost always" & 7.6 & 2.8 & 2.27 & $1.5-4.9$ \\
$\quad$ "some times" & 16.5 & 10.0 & 1.64 & $1.2-2.8$ \\
$\quad$ "some times and have & & & & \\
$\quad$ seen a doctor for it" & 8.4 & 4.9 & 1.70 & $1.03-2.8$ \\
Subjective heart function & & & & \\
$\quad$ "Very good" & 32.7 & 41.5 & 0.76 & $0.7-1.0$ \\
$\quad$ "So and so" & 14.4 & 10.6 & 1.37 & $1.0-2.0$ \\
$\quad$ "Not quite good or worse" & 2.0 & 1.8 & 1.23 & $0.5-3.3$ \\
Hospitalized due to CVD & 22.4 & 23.5 & 0.92 & $0.5-1.6$ \\
\hline
\end{tabular}


Table 3. Prevalences of chronic bronchitis and respiratory symptoms directly adjusted for age and smoking habits in 236 stainless steel metal workers (study group) and a control group of 989 men from the general population.

\begin{tabular}{lcccc}
\hline $\begin{array}{l}\text { Chronic bronchitis/ } \\
\text { respiratory symptoms }\end{array}$ & $\begin{array}{c}\text { Study group } \\
(\mathrm{n}=236)\end{array}$ & $\begin{array}{c}\text { Control group } \\
(\mathrm{n}=989)\end{array}$ & $\begin{array}{c}\text { Prevalence } \\
\text { ratio }\end{array}$ & $\begin{array}{c}95 \% \text { confidence } \\
\text { interval }\end{array}$ \\
\hline Chronic bronchitis & 9.2 & 7.8 & 1.16 & $0.73-1.84$ \\
$\begin{array}{l}\text { Cough with phlegm in the } \\
\text { morning or during the day }\end{array}$ & 14.8 & 12.3 & 1.19 & $0.83-1.69$ \\
Light dyspnoe & 14.8 & 12.3 & 1.19 & $0.84-1.70$ \\
Severe dyspnoe & 3.7 & 2.7 & 1.47 & $0.70-3.09$ \\
Attacs of dyspnoe with wheezing & 7.2 & 6.0 & 1.21 & $0.70-2.10$ \\
\hline
\end{tabular}

When comparing the answers in the questionnaires regarding CVD with the prevalence of similar diseases registered with their appointed general practitioners of 85 randomly selected men from the study group and 203 from the control group, angina pectoris (as stated in a colloquial way by the participants) showed a sensitivity of $22 \%$ and $29 \%$, and a specificity of $100 \%$ and $80 \%$ respectively. For the question about myocardial infarction the sensitivities were $100 \%$ and $90 \%$ respectively, and the specificity $90 \%$ in both groups.

Outcome variables consistent with IHD were chosen for further analyses by multiple logistic regression. The main independent variables in these analyses were the study group versus the control group, and length of employment at the plant (table 4), exposure subgroups (table 5), and specific exposures (table 6). In addition to the main independent variables, age, amount of current smoking, length of education, and first degree relatives with CVD under the age of 50 years were included as independent variables in the models. All odds ratios in the tables 4-6 are thus adjusted for these potential confounding factors.

Table 4 shows odds ratios derived by the logistic regression analysis for the study group versus the control group, and for 10 years of employment at the plant. For all three outcome variables the study group had statistically significant increased odds ratios when compared to the control group. For chest pain on exercise and myocardial infarction there was also a positive relation with length of employment at the plant.

When men from the study group who were considered as indirectly exposed and those who were considered as directly exposed with regard to welding and grinding were compared with the control group, both groups had increased odds ratios with the highest values among the indirectly exposed for angina pectoris and myocardial infarction (table 5). For the directly exposed there was a statistically significant relation between length of employment and chest pain on exercise with an odds ratio for 10 years of $1.3(95 \%$ CI 1.1-1.6).

Table 6 presents odds ratios for specific work related exposures/activities as stated in the questionnaires. Any welding reported, and stainless steel welding, did not show statistically significant increased odds ratios for any of the outcome variables. The only reported activity that shows statistically significant increased odds ratios for all three outcome variables was work with grinding. The duration of grinding work was also statistically significantly related to chest pain on exercise with an odds ratio for 10 years of grinding of 2.4 (95\% CI 1.0-5.5) and to myocardial infarction with an odds ratio for the same amount of time of 1.6 (95\% CI 1.1-2.3).

When tested with the same logistic regression model as we used in table 4-6, other independent variables which were inquired about in the questionnaire reflecting exposure to noise, heat stress, vibration, fluorocarbons, and shift work did not show statistically significant relations with any of the three selected outcome variables.

\section{DISCUSSION}

This study observed an increased risk of IHD in stainless steel metal workers even when potential confounding factors were controlled for. It was also found that the increased risk for some of the outcome variables was related to the length of employment at the plant. There was no evidence of an increased risk of other CVD than IHD.

The study is a historical cohort study including men who since 1960 had been working for at least one year at the plant, and who, at the time of the study were under 70 years of age. The outcome was measured as a cross-section in 1993. However, as we inquired about previous myocardial infarctions, and since other CVD also have certain chronic features, we find it right also to view the outcome variables in a semi-longitudinal perspective.

If there has been an increased risk of CVD in the study group which was recruited from 1960 on, this should also have been reflected in mortality/survival up to the time of the study. If so, selection bias which can have arised from such a difference has probably to a small extent weakened the contrast between the study group and the control group.

As the study compares blue collar workers with the general population, there might also be a selection of healthy workers into the study group. We minimalize this error by the exclusion of men who had not been occupationally active from the control group which 
was recruited from the general population. However, if there still is such a selection bias, this will also have underestimated the true relative risk. On the other hand, there were indicators from the educational status in the two groups that the control group had a different social composition than the study group, which in case will have had an opposite effect on the relative risks observed. Therefore, length of education was controlled for in the logistic regression analyses.

When both independent and dependent variables are measured by means of a questionnaire, as in the present study, some misclassification of the variables is unavoidable. From the comparision of the answers with information from the general practitioners we have, however, reason to believe that the misclassification, at least regarding the outcome variables, was non-differential. In that case the misclassification has probably also led to a bias of the observed relative risks towards one.
As work with welding entails exposure to smoke and gases that are known respiratory irritants, it might be that the cardiac symptoms stated in reality were expressions of respiratory disturbances. When inquiring about respiratory symptoms in the questionnaire we found only very weak indications of an increased prevalence of respiratory symptoms in the study group (table 3). Therefore we do not think that respiratory disturbances are the explanation of the observed differences in IHD.

With the limited number of participants and the expected low prevalence of CVD, the study had a low statistical power. This is probably the main reason for the wide confidence intervals observed. The low statistical power does not speak against the significant differences that were found, but it might be that other comparisons which showed increased prevalences, but of non-statistical significance, might have shown statistical significance if the study group had been larger.

Table 4. Odds ratios and $95 \%$ confidence intervals as determined by multiple logistic regression for outcome variables consistent with IHD for the study group versus the control group, and for 10 years of employment at the plant. Age, amount of current smoking, length of education, and first degree relatives with CVD under the age of 50 were included in the regression models as potential confounding factors.

\begin{tabular}{lccc}
\hline & \multicolumn{3}{c}{ Outcome variables } \\
\cline { 2 - 4 } Independent variables & Chest pain on exercise & Angina pectoris & Myocardial infarction \\
\hline Study group versus control group & $2.6(1.3-5.3)$ & $2.5(1.1-5.8)$ & $2.4(1.1-4.9)$ \\
Ten years of employment at the plant & $1.4(1.0-1.8)$ & $1.1(0.7-1.7)$ & $1.3(1.0-1.7)$ \\
\hline
\end{tabular}

Table 5. Odds ratios and $95 \%$ confindence intervals as determined by multiple logistic regression for outcome variables consistent with IHD for directly and indirectly exposed members of the study group as compared with the unexposed. Age, amount of current smoking, length of education, and first degree relatives with CVD under the age of 50 were included in the regression models as potential confounding factors.

\begin{tabular}{lccc}
\hline & \multicolumn{3}{c}{ Outcome variables } \\
\cline { 2 - 4 } Exposure groups & Chest pain on exercise & Angina pectoris & Myocardial infarction \\
\hline Indirectly exposed & $2.3(0.6-8.9)$ & $3.0(0.6-13.9)$ & $3.6(1.1-11.5)$ \\
Directly exposed & $2.4(1.0-5.6)$ & $2.1(0.7-6.1)$ & $2.4(1.0-5.9)$ \\
\hline
\end{tabular}

Table 6. Odds ratios and $95 \%$ confindence intervals as determined by multiple logistic regression for outcome variables consistent with IHD for specific exposure factors or actvities. Age, amount of current smoking, length of education, and first degree relatives with CVD under the age of 50 were included in the regression models as potential confounding factors.

\begin{tabular}{lccc}
\hline & \multicolumn{3}{c}{ Outcome variables } \\
\cline { 2 - 4 } Independent variables & Chest pain on exercise & Angina pectoris & Myocardial infarction \\
\hline Any welding & $1.8(0.7-4.3)$ & $1.4(0.5-4.2)$ & $1.8(0.7-4.4)$ \\
Stainless steel welding & $1.8(0.7-4.6)$ & $1.6(0.5-5.0)$ & $1.8(0.7-4.7)$ \\
Grinding & $2.4(1.0-5.5)$ & $3.3(1.3-8.5)$ & $2.5(1.1-5.9)$ \\
Insulation with foam & $1.8(0.3-3.8)$ & $2.3(1.03-5.0)$ & $4.0(2.2-7.2)$ \\
\hline
\end{tabular}


The study was able to show differences between the groups, and a relationship with length of employment, but when comparing the exposure categories the study did not show an exposure-response relationship. This weakens the possible evidence for a causal relationship between exposure factors at the plant and the occurrence of IHD. One explantion for these negative results might be that all workers were exposed, but that those not working directly with welding and grinding were less prone to use personal and other protective equipement. The results might also be a reflection of the circumstance that a crude exposure assessment in an epidemiological study always will be encumbered with uncertainty.

In the analysis of specific work activities, work with grinding was the only explanatory variable that showed statistically significant increased odds ratios for all three outcome variables consistent with IHD. Work with welding did not show statistically significant increased odds ratios for any of the outcome variables. As welding was our primary concern when starting the study, this was a surprising result. In one other Norwegian study it has, however, been shown that exposure to metals like iron, nickel and total chromium was greater in stainless steel grinders than in welders (11). The increased risk in grinders is also interesting in view of the hypothesis that inhalation of very fine particles may influence the blood coagulability (8).
So far, the knowledge about a possible relation between metal work and the risk of CVD has been limited. To some extent our results are in accord with the mortality data found among British shipyard welders (5), and among French welders (6). The recent register study of mortality from IHD from Sweden and Denmark (7) may also support a hypothesis that there is a relation between certain factors to which metal workers are exposed and IHD. More research, both epidemiological and experimental, is needed in order to further elucidate that possibility.

\section{CONCLUSION}

The results of the present study support a hypothesis that there might be a relation between exposure factors to which stainless steel metal workers are exposed and the risk of IHD.

\section{ACKNOWLEDGMENTS}

We wish to express our gratitude to Randi Wisth Dalseg from Lade Occupational Health Service and Terje Foosnæs from Landteknikk AS who came up with the idea that initiated the study and supported us in conducting it. We also thank Heidi Holt at Landteknikk AS who provided us with all names from the personell register at the plant. Tormod Schanke, MD, conducted the evaluation of the outcome variables with the general practitioners. We also wish to thank Patrica Flor for her linguistic help. The study was to some extent supported with grants from the Norwegian National Health Association.

\section{REFERENCES}

1. Kristensen TS. Cardiovascular diseases and the work environment - A critical review of the epidemiologic literature on chemical factors. Scand J Work Environ Health 1989; 15: 145-64.

2. Steenland A. Epidemiology of occupation and coronary heart disease: Research agenda. Am J Ind Med 1996; 30: $495-9$.

3. Theorell T. Stress at work and risk of myocardial infarction. Postgrad Med J 1986; 62: 791-5

4. Kristensen TS. Cardiovascular diseases and the work environment - A critical review of the epidemiologic literature on nonchemical factors. Scand J Work Environ Health 1989; 15: 165-79.

5. Newhouse ML, Oakes D, Woolley AJ. Mortality of welders and other craftsmen at a shipyard in NE England. Br J Ind Med 1985; 42: 406-10.

6. Moulin JJ, Wild P, Haguenoer JM, Faucon D, Gaudemaris De R, Mur JM, et al. A mortality study among mild steel and stainless steel welders. Br J Ind Med 1993; 50: 234-43.

7. Bach E, Alfredsson L, Hammar N, Tüchsen F. Acute myocardial infarction in selected occupations in Denmark and Sweden. Book of abstracts part 2. 25th International Congress on Occupational Health, Stockholm, Sweden, Sept. 15-20, 1996. Stockholm, National Institute of Working Life, 1996, p. 164.

8. Sjögren B. Occupational exposure to dust: inflammation and ischaemic heart disease. Occup Environ Med 1997; 54: 466-9.

9. Thelle DF, Arnesen E, Førde OH. Does coffee raise serum colesterol? N Engl J Med 1983; 308: 1454-7.

10. Medical Research Council's Committee on Research into Chronic Bronchitis. Questionnaire on respiratory symptoms. London: Medical Research Council, 1966.

11. Karlsen JT, Torgrimsen T, Langård S. Exposure to solid aerosols during regular MMA welding and grinding operations on stainless steel. Am Ind Hyg Assoc J 1994; 55: 1149-53. 